\title{
Monitoring Skeletal Anomalies in Big-Scale Sand Smelt, Atherina boyeri, as a Potential Complementary Tool for Early Detection of Effects of Anthropic Pressure in Coastal Lagoons
}

\author{
Chiara Leone, Francesca De Luca *, Eleonora Ciccotti, Arianna Martini (D) and Clara Boglione (D) \\ Dipartimento di Biologia—Università degli Studi di Roma "Tor Vergata”, Via della Ricerca Scientifica 1, \\ 00133 Rome, Italy; chiara.leone@uniroma2.it (C.L.); ciccotti@uniroma2.it (E.C.); \\ ariannamartini.89@gmail.com (A.M.); boglione@uniroma2.it (C.B.) \\ * Correspondence: francesca.b.deluca@gmail.com; Tel.: +39-06-7259-5967
}

check for updates

Citation: Leone, C.; De Luca, F.; Ciccotti, E.; Martini, A.; Boglione, C. Monitoring Skeletal Anomalies in Big-Scale Sand Smelt, Atherina boyeri, as a Potential Complementary Tool for Early Detection of Effects of Anthropic Pressure in Coastal Lagoons. Water 2021, 13, 159. https://doi.org/10.3390/w13020159

Received: 30 November 2020 Accepted: 9 January 2021 Published: 12 January 2021

Publisher's Note: MDPI stays neutral with regard to jurisdictional clai$\mathrm{ms}$ in published maps and institutional affiliations.

Copyright: $\odot 2021$ by the authors. Licensee MDPI, Basel, Switzerland. This article is an open access article distributed under the terms and conditions of the Creative Commons Attribution (CC BY) license (https:// creativecommons.org/licenses/by/ $4.0 /)$.

\begin{abstract}
Mediterranean coastal lagoons are increasingly affected by several threats, all concurrently leading to habitat degradation and loss. Methods based on fish for the assessment of the ecological status are under implementation for the Water Framework Directive requirements, to assess the overall quality of coastal lagoons. Complementary tools based on the use of single fish species as biological indicators could be useful as early detection methods of anthropogenic impacts. The analysis of skeletal anomalies in the big-scale sand smelt, Atherina boyeri, from nine Mediterranean coastal lagoons in Italy was carried out. Along with the morphological examination of fish, the environmental status of the nine lagoons was evaluated using a method based on expert judgement, by selecting and quantifying several environmental descriptors of direct and indirect human pressures acting on lagoon ecosystems. The average individual anomaly load and the frequency of individuals with severe anomalies allow to discriminate big-scale sand smelt samples on the basis of the site and of its quality status. Furthermore, a relationship between skeletal anomalies and the environmental quality of specific lagoons, driven by the anthropogenic pressures acting on them, was found. These findings support the potentiality of skeletal anomalies monitoring in big-scale sand smelt as a tool for early detection of anthropogenic impacts in coastal lagoons of the Mediterranean region.
\end{abstract}

Keywords: biological indicator; anthropogenic impacts; mediterranean coastal lagoons; resident species; skeletal anomalies

\section{Introduction}

The big-scale sand smelt Atherina boyeri is a small, short-lived euryhaline fish species, widely distributed throughout the Mediterranean and Black Sea [1] and in the eastern Atlantic Ocean [2]. It usually spends its life cycle in coastal and brackish environments [3] but also can dwell in freshwater habitats [4] and hypersaline conditions [5]. The big-scale sand smelt is a gregarious species and carnivorous, feeding on small crustaceans, worms, molluscs, and fish larvae [6]. For this reason, it is considered as one of the main links between primary benthic and planktonic consumers and the higher trophic level in the food-webs of the aquatic habitats it inhabits [7]. Because of the morphological variability $[3,8,9]$ and polymorphism [10-13] of the species, the taxonomy of the genus Atherina is still controversial. Several studies based on morphological [12], biochemical [13], and molecular investigations $[14,15]$ have identified three distinct groups that have been proposed to be elevated to the rank of species [16]: one corresponding to the lagoon type (A. lagunae, [16]) and two of marine type: non-punctuated (A. boyeri, [16]) and punctuated (A. punctata, [16]). However, the terminology is not validated, and many studies, especially ecological investigations where no morphological and genetic analyses are performed, still refer to the A. boyeri complex. 
A. boyeri is a typical resident fish in most Mediterranean coastal lagoons, along with other small sized fish such as the pipefish (Sygnatus spp.), the killifish (Aphanius fasciatus), the blenny (Salaria pavo), and many Gobiid species. Resident fish are numerically dominant in lagoon fish assemblages $[17,18]$, and although generally without economic value, they play an important role as key links in the lagoon food web. A. boyeri is the only resident fish exploited by Mediterranean lagoon fisheries, that mostly target marine seasonal migrants, such as many species from Sparidae, Mugilidae, and Moronidae families, and the catadromous species Anguilla anguilla [1,19-21].

In the Mediterranean region, lagoon fisheries have always been important from both the socio-economic and the cultural points of view, and still represent a main provisioning ecosystem service delivered by lagoon ecosystems [22-25]. These include biodiversity conservation, as well as cultural and recreational services, and regulating and supporting services such as protection by coastal erosion, flood control, and waste and pollution assimilation. Lagoon ecosystem services provision relies on the strategic location in the coastal area as well as on the ecological features of these transitional water bodies [21,26]. Due to their intermediate position between the continental and marine domain, coastal lagoons show significant ecological gradients that make these environments very dynamic, at the temporal and spatial scale, and highly resilient and productive. On the other hand, precisely because of their position between land and sea, and along with the increase of human activities and consumption patterns, lagoons are increasingly affected by several threats $[27,28]$. These can directly or indirectly lead to changes in the structure and functioning of these ecosystems, as well as to habitat degradation and loss. Therefore, the need to assess the overall quality of coastal lagoons considering anthropogenic impacts affecting their ecological status has become a priority.

Fish have been widely used to assess habitat alterations and describe the characteristic of the aquatic ecosystem [29] based on a number of reasons (e.g., sensitivity to stressors, longevity, complex habitat requirements) [30-33]. The long-standing tradition of ecological, physiological, and ecotoxicological research on a large number of fish species [34-36] has allowed to provide insight into environmental degradation at different levels. Since the issuing of the Water Framework Directive (WFD, 2000/06/EC) [37], the interest has shifted towards a global evaluation of the ecological status of aquatic ecosystems. The WFD implementation now also foresees the use of fish as Biological Quality Element (BQE), and this has driven towards the development of suitable methodologies to include fish in the evaluation of the quality status of aquatic ecosystems [38-40]. For transitional waters, and specifically for lagoons, methods based on fishes are still under validation. Potential methods rely on the use of multi-metric indices that take into account the fish assemblage as a whole, and supplementary information (e.g., environmental parameters and human activities) to evaluate anthropogenic pressures acting on the lagoon [40-42].

On the other hand, [43] have been recently pointing out that an approach based on the use of a single fish species as a biological indicator, in comparison with the use of fish assemblages as a whole, remains valid. Information from single fish populations addressing health, condition status or contamination might be used as complementary information on habitat environmental conditions. Particularly for transitional water bodies, especially wetlands and coastal lagoons, resident fish are considered the most suitable [43] indicator species of lagoon environmental conditions [36,43,44]. They spend their entire life cycle within the water basin [1], and they can integrate the effects of natural environmental stress of the ecosystem [20] and those of pressures deriving from human activities [18,45], with responses at the different levels of the biological organization [46].

Within the many levels of investigation supporting the use of fish as bioindicators of environmental degradation (see [29] for a review), morphological anomalies and skeletal anomalies in fish have been proposed [47-49] as potential easily detectable indicators of a disturbed development possibly related to environmental disturbance. Skeletal anomalies are taken into account in one of the first proposed multi-metric index based on fish fauna to evaluate anthropogenic pressures acting on water bodies, the Index of Biotic Integrity 
(IBI) [50]. The IBI includes among indicators the presence of DELT anomalies, stated as the ratio of fish specimens with deformities, fin erosion, lesions, and tumors [51]. The development of skeletal anomalies is a process that can occur along the entire life cycle of a fish (larva, juvenile, and adult). Moreover, the skeleton is a system characterized by high plasticity, whose anatomy, histology, mechanical properties, and number of elements depend on environmental and genetic factors [52]. The influence of environmental, genetic, and epigenetic factors on the skeleton is further modulated by the ecology, biology, and physiology of fish. Morphological anomalies are rare in natural populations from undisturbed ecosystems, but many authors have hypothesized a relationship between skeletal anomalies and environmental conditions $[47,50,53,54]$. As a result, skeletal anomalies in fish have been used as biomarkers of pollution stress [55-57].

Skeletal deformities (lordosis, scoliosis, etc.) have been detected in the big-scale sand smelt and related to contamination by pollution [58-60] and environmental factors [61]. This fish is described as very sensitive to water quality, responding rapidly to its deterioration [1]. Several studies identify the big-scale sand smelt as key fish species to reveal potential contamination (physiological biomarkers, biochemical and genotoxic biomarkers: [62]) and to evaluate the overall environmental quality (body condition [43]) in transitional water ecosystems.

In the present study, skeletal anomalies in $A$. boyeri complex from nine Mediterranean coastal lagoons in Italy are examined, and their prevalence, frequencies, typologies, and severity evaluated on a comparative basis. The nine study sites have been chosen on the basis of their typology, and of the environmental and management setting. Their quality status is assessed by a methodology based on expert judgement approach that relies on several environmental descriptors of direct and indirect human pressures acting on lagoon ecosystems. The results of the skeletal anomalies analysis in the nine big-scale sand smelt populations are compared with the results obtained from the quality status assessment of the nine lagoons. The aims of the study were: (i) to analyze and describe the skeletal condition of the $A$. boyeri complex in different populations (ii) to verify if the analysis of skeletal anomalies in this resident species allow s for detecting the presence of anthropogenic pressures on coastal lagoons, thus contributing to the assessment of the ecological status in Mediterranean transitional waters.

\section{Materials and Methods}

\subsection{Study Sites}

The study sites are nine coastal lagoons along the coasts of Italy (Figure 1), chosen on the basis of their ecological and socio-economical relevance. Orbetello (ORB), Fogliano (FOG), Caprolace (CAP), and Sabaudia (SAB) are on the Tyrrhenian coast, while Grado Marano (GRA), Goro (GOR), and Comacchio (COM) are located in the Northern Adriatic area. Lesina (LES) is in the Southern Adriatic region, and Cabras (CAB) is located in Sardinia, the second largest island in the Mediterranean Sea. All lagoons are Special Protection Areas (SPAs) and Special Areas of Conservation (SACs), designated respectively under the Birds Directive (79/409/CEE) and the Habitats Directive (92/43/CEE) [63], and hence included in the Natura 2000 network of protected areas. The main geo-morphological and hydrographic features of the nine coastal lagoons are reported in Table 1.

\subsection{Environmental Assessment}

The lagoons' overall environmental quality was assessed using a method based on expert judgement [64], whose background, rationale and methodology are detailed in [65]. The method relies on the preliminary choice, by subjective expert judgement, of several indicators of direct and indirect human pressure acting on the lagoon ecosystems, which are quantified on a range scale (from 0-not present to 5-very high). These concur to the objective scoring of values of three Category Pressure Indexes, CPIs, related to three categories of anthropogenic pressure: "Changes in morphology and hydrology" (CPI-Morpho), "Use of landscape and lagoon resources" (CPI-Use) and "Water quality" (CPI-Qual). CPIs scores 
concur in turn to the calculation of a Final Pressure Index, FPI. For a detailed description of the choice of pressure indicators for the lagoons under study, their attribution to categories and their quantification, data sources, and formulas for the CPIs and FPI calculation, see Section S1 in Supplementary Material file and [65].

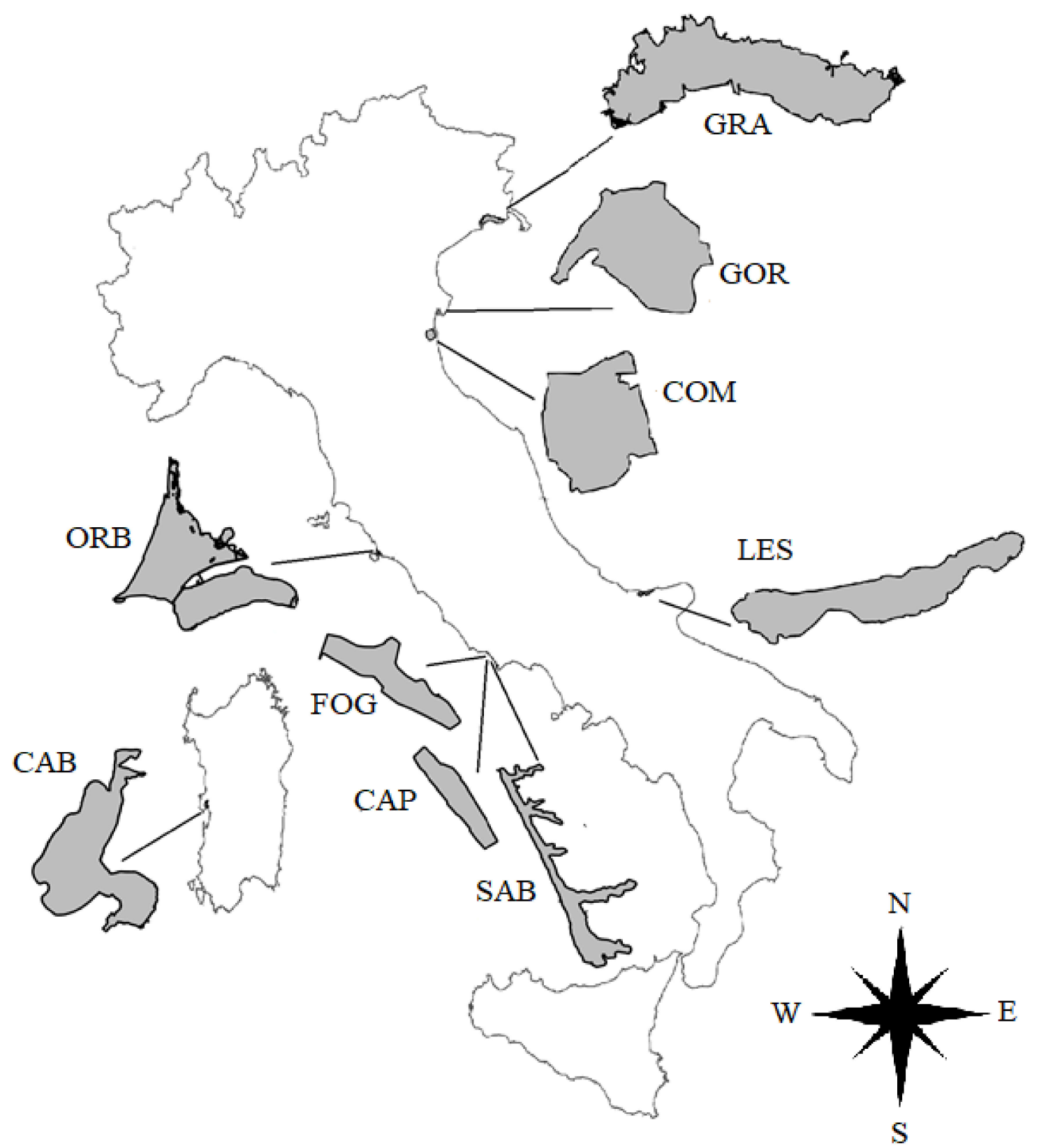

Figure 1. Map of Italy, and location of the nine coastal lagoons under study (not in scale). (ORB) Orbetello, (CAB) Cabras, (FOG) Fogliano, (CAP) Caprolace, (SAB) Sabaudia, (LES) Lesina, (COM) Comacchio, (GOR) Sacca di Goro, (GRA) Grado Marano. 
Table 1. Main geo-morphological and hydrographic features of coastal lagoons under study. (ORB) Orbetello, (CAB) Cabras, (FOG) Fogliano, (CAP) Caprolace, (SAB) Sabaudia, (LES) Lesina, (COM) Comacchio, (GOR) Sacca di Goro, (GRA) Grado Marano.

\begin{tabular}{|c|c|c|c|c|c|c|c|c|c|}
\hline & ORB & САВ & FOG & CAP & SAB & LES & COM & GOR & GRA \\
\hline Latitude & $42^{\circ} 26^{\prime}$ & $39^{\circ} 57$ & $41^{\circ} 24^{\prime}$ & $41^{\circ} 21^{\prime}$ & $41^{\circ} 16^{\prime}$ & $41^{\circ} 53^{\prime}$ & $44^{\circ} 34^{\prime}$ & $41^{\circ} 16^{\prime}$ & $45^{\circ} 44^{\prime}$ \\
\hline Longitude & $11^{\circ} 11^{\prime}$ & $8^{\circ} 29^{\prime}$ & $12^{\circ} 54^{\prime}$ & $12^{\circ} 58^{\prime}$ & $13^{\circ} 02^{\prime}$ & $15^{\circ} 26^{\prime}$ & $12^{\circ} 13^{\prime}$ & $13^{\circ} 02^{\prime}$ & $13^{\circ} 15^{\prime}$ \\
\hline Perimeter $(\mathrm{km})$ & 41 & 40 & 11.2 & 8.4 & 20,1 & 48 & 52.90 & 36.3 & 74 \\
\hline Surface (ha) & 2700 & 2200 & 404 & 226 & 400 & 5140 & 11,540 & 3700 & 16,364 \\
\hline Max Depth (m) & 1.70 & 2.1 & 2 & 2.9 & 10 & 1.60 & 2 & 2 & 12 \\
\hline Mean Depth (m) & 1 & 1.6 & 0.89 & 1.3 & 4.5 & 0.90 & 0.60 & 0.60 & 1.12 \\
\hline Volume $\left(\mathrm{m}^{3}\right)$ & $27,000,000$ & $33,600,000$ & $3,616,000$ & $2,923,783$ & $14,000,000$ & $4,626,000$ & $10,000,000$ & $39,500,000$ & $144,000,000$ \\
\hline Inlet $\left(\mathrm{n}^{\circ}\right)$ & 3 & 1 & 2 & 2 & 2 & 2 & 3 & 1 & 6 \\
\hline Tributary $\left(\mathrm{n}^{\circ}\right)$ & 1 & 2 & 0 & 0 & 3 & 3 & 3 & 5 & 11 \\
\hline Tidal Range (cm) & 35 & 28 & 23 & 21 & 20 & 30 & 20 & 90 & 90 \\
\hline $\begin{array}{l}\text { Annual Average } \\
\text { Temperature }\left(\mathrm{C}^{\circ}\right)\end{array}$ & 16 & 18.2 & 21.2 & 19.4 & 19.7 & 18 & 20 & 17 & 15.6 \\
\hline $\begin{array}{c}\text { Annual Average } \\
\text { Salinity (PSU) }\end{array}$ & 35.5 & 20 & 40.5 & 39 & 29 & 21.5 & 29 & 22 & 29 \\
\hline $\begin{array}{l}\text { Water exchange } \\
\text { rate (days) }\end{array}$ & $>250$ & 122 & 60 & 90 & 300 & $<250$ & 115 & 5 & $>100$ \\
\hline \multirow{3}{*}{$\begin{array}{c}\text { WFD } \\
\text { classification }\end{array}$} & Non-tidal & Non-tidal & Non-tidal & Non-tidal & Non-tidal & Non-tidal & Non-tidal & Tidal & Tidal \\
\hline & Euryhaline & Polyhaline & Iperhalyne & Euryhaline & Polyhaline & Polyhaline & Polyhaline & Polyhaline & Polyhaline \\
\hline & Large $*$ & Large & Large & Small ** & Large & Large & Large & Large & Large \\
\hline
\end{tabular}

${ }^{*}$ Large $\geq 2.5 \mathrm{~km}^{2} ;{ }^{* *}$ Small $\leq 2.5 \mathrm{~km}^{2}$.

\subsection{Fish Samplings and Preparation}

Fish samplings were carried out between 2014-2017. In all sites, big-scale sand smelts are exploited by commercial fisheries, except two (Fogliano and Caprolace). Therefore, 97-135 individuals were taken from commercial catches or scientific surveys at each site. A total of 1023 fish were painlessly euthanized by lethal anaesthesia with 2-phenoxy ethanol $4 \%$ and fixed in buffered formalin $10 \%$ ( $\mathrm{pH} 7.2 ; 0.1 \mathrm{M})$.

Individual standard length (SL, $\mathrm{mm}$ ) was measured on digital images using the software ImageJ (https://imagej.nih.gov/ij/download.html). Specimens were whole mount stained for calcified tissues with Alizarin red S (modified from [66]) and stored in $100 \%$ glycerol. Individuals were examined for skeletal anomalies detection using a Leica MZ12 Stereo Zoom Microscope.

\subsection{Analysis of Skeletal Anomalies}

Skeletal anomalies were classified using an alphanumeric code following $[57,67]$. For the complete list of skeletal anomalies and the relative binomial key, see Table 2 . The anatomical terminology is according to [68].

Table 2. List of the considered skeletal anomalies types. The letter indicates the body region; the number indicates the anomaly type, and the symbols *, \# indicate a variation (or a sub-type) of the anomaly type. Severe anomalies are shown in bold.

\begin{tabular}{ccc} 
& A & Cephalic vertebrae (carrying epipleural ribs) \\
\cline { 2 - 3 } Region & Abdominal vertebrae (carrying epipleural and pleural ribs and with open hemal arch, without hemal spine) \\
\hline C & Hemal vertebrae (with hemal arches closed by hemal spines) \\
\hline D & Caudal vertebrae (with hemal and neural arches closed by modified, elongated spines) \\
\hline E & Pectoral fin \\
\hline F & Anal fin \\
\hline
\end{tabular}


Table 2. Cont.

\begin{tabular}{|c|c|c|}
\hline & G & Caudal fin \\
\hline & $\mathrm{H}$ & First dorsal fin \\
\hline & I & Second dorsal fin \\
\hline & $\mathrm{L}$ & Pelvic fin \\
\hline & $\mathrm{M}$ & Interdorsal elements between first and second dorsal fin \\
\hline \multirow{38}{*}{ Typology of anomaly } & $\mathrm{S}$ & Scoliosis \\
\hline & 1 & Lordosis \\
\hline & 2 & Kyphosis \\
\hline & 3 & Partial vertebrae fusion \\
\hline & $3 *$ & Complete vertebrae fusion \\
\hline & 4 & Malformed vertebral body \\
\hline & $4 z$ & Malformed zygapophysis \\
\hline & 5 & Malformed neural arch and/or spine \\
\hline & $5 *$ & Supernumerary neural arch and/or spine \\
\hline & $5 \#$ & Absent neural arch and/or spine \\
\hline & 6 & Malformed hemal arch and/or spine and/or rib \\
\hline & $6 \mathrm{~T}$ & Tulip-like shaped hemal arch \\
\hline & $6^{*}$ & Supernumerary hemal arch and/or spine and/or rib \\
\hline & $6 \#$ & Absent hemal arch and/or spine and/or rib \\
\hline & 7 & Malformed or absent pleural ribs \\
\hline & $7 *$ & Supernumerary pleural rib \\
\hline & 8 & Malformed pterygiophore (deformed, absent, fused, supernumerary) \\
\hline & $8^{*}$ & Malformed interdorsal element \\
\hline & 9 & Malformed hypural (deformed, absent, fused, supernumerary) \\
\hline & $9 *$ & Malformed parahypural (deformed, absent, fused, supernumerary) \\
\hline & 10 & Malformed epural (deformed, absent, fused, supernumerary) \\
\hline & $10 *$ & Hypermineralized epural \\
\hline & 11 & Malformed ray (deformed, absent, fused, supernumerary) $(\mathrm{R}=$ right; $\mathrm{L}=\mathrm{Left})$ \\
\hline & 14 & Malformed pre-maxillary and/or maxillary \\
\hline & 15 & Malformed dental \\
\hline & 16 & Other splanchno-cranium anomalies \\
\hline & 17 & Deformed or reduced opercular plate $(\mathrm{R}=$ right, $\mathrm{L}=$ left $)$ \\
\hline & 17 * & Deformed, absent, fused branchiostegal ray $(\mathrm{R}=$ right, $\mathrm{L}=$ left $)$ \\
\hline & 19 & Hypural with demineralization \\
\hline & $19^{*}$ & Hypermineralized hypural \\
\hline & 20 & Hypermineralized pterygiophore \\
\hline & 24 & Opercular plate with decalcification $(\mathrm{R}=$ right side, $\mathrm{L}=$ left side $)$ \\
\hline & 25 & Epural with decalcification \\
\hline & 26 & Hypermineralized vertebral arch \\
\hline & 27 & Urostyle with decalcification \\
\hline & 28 & Malformed radial \\
\hline & Cor & Malformed coracoid $(\mathrm{R}=$ right, $\mathrm{L}=$ left $)$ \\
\hline & Sca & Malformed scapula $(\mathrm{R}=$ right, $\mathrm{L}=$ left $)$ \\
\hline
\end{tabular}

The data obtained from the monitoring of the skeletal anomalies were used to build a matrix (RM, i.e., raw data matrix). The RM was transformed into a binary matrix (BM, i.e., presence of each type of skeletal malformation $=1$; absence $=0$ ). The RM was used to 
calculate the frequencies (\%) of each type of anomaly on the total number of anomalies. The BM was used to calculate the frequencies (\%) of the individuals affected by each type of anomaly in each group. For each fish sample, the following metrics were calculated: (i) frequency (\%) of individuals with at least one anomaly; (ii) average anomaly load, as number of observed anomalies/number of individuals with anomalies; iii) number of observed types of anomalies; (iv) frequency (\%) of individuals with at least one severe anomaly (axis deformation, cephalic anomalies, vertebral centra fusions and deformations); (v) average severe anomaly load, as number of severe anomalies/number of individuals with severe anomalies; and (vi) percentage of severe anomalies, as the ratio of the number of severe anomalies over the number of total anomalies.

\subsection{Data Analysis}

To interpret and compare results of the lagoons environmental assessment, a Principal Components Analysis (PCA) [69] was run on the dataset relative to scores of all pressure indicators in each site. Fish standard lengths (SL) were compared with the Kruskal-Wallis test followed by Mann-Whitney pairwise test with the Bonferroni correction. Differences in SL among samples were considered significant for a $p$-value $<0.05$.

Correspondence analyses (CA) [70] were carried out on the RM and other matrices laid out with sub-set of data to highlight the possible role of anomalies types in discriminating fish samples by the site of origin. As a final step, in order to explore potential relationships among the categorical variables taken into account, i.e., (a) the skeletal anomalies presence in fish, (b) the anthropogenic pressures in the nine study sites, (c) the site of origin of the samples, a Multiple Correspondence Analysis (MCA) [71] was carried out. Based on anomalies' absolute contribution to the CA ordination model, six anomalies were retained for the MCA, i.e., B4z, B5, C6T, E11L, G11, M8*. The dataset of active variables brought together (a) the binary codes (0/1) for the presence of the six selected anomalies) and (b) the anthropogenic pressure indicators. For the latter, each variable (single pressure indicator) was coded with several columns, relative to each possible score (from 0 to 5 ) for each of the 13 indicators, and removing variables with no variance (all 0 , all 1 ), thus obtaining a total of 45 columns for the environmental variables. For example, the Water renewal time indicator $(\mathrm{EXC})$ is inflated in 5 variables, i.e., $\mathrm{EXC} / 0 \ldots \mathrm{EXC} / 5$ corresponding to 5 possible scores. The final binary matrix consisted of 842 rows, i.e., fish presenting at least one of the six selected anomalies, $x 51$ columns, 6 relative to the presence/absence of each retained anomaly and 45 to the occurrence or not of pressure indicators score levels. One supplementary variable was added to represent the study sites from which fish were sampled.

All statistical procedures were performed with Past v.4.03 software [72], except the MCA that was carried out in R 3.6.0 using the FactorMine package.

\section{Results}

\subsection{Environmental Assessment}

The results of the lagoons environmental assessment are reported in Figure 2, where the scores attributed to the 13 pressure indicators are given in radar plots for each lagoon under study. In Table 3, the scores calculated for the three CPIs and FPIs for each lagoon are also given. The level of anthropic impact is not high in any of the nine lagoons under study: FPI values (which can vary between 0 and 65) are between 22 and 35. LES and CAP are the least impacted, with FPIs of 22 and 23, standing for a low anthropogenic impact. The other lagoons all show an intermediate anthropogenic impact condition, with COM, SAB and GOR with higher FPI scores (35, 33, and 30, respectively), and ORB, CAB, FOG, and GRA showing intermediate FPI scores (27-28). The overall level of anthropogenic impact observed in the various lagoons is then essentially similar, but in the nine lagoons, the types of pressures contributing to the observed impact are different. Pressures related to the CPI-Morpho are the most relevant in FOG and COM, and those related to CPI-Use 
in $\mathrm{CAB}, \mathrm{SAB}$, and GOR. Only the CPI-Qual contributes similarly, and quite considerably, to the FPIs in all nine lagoons.
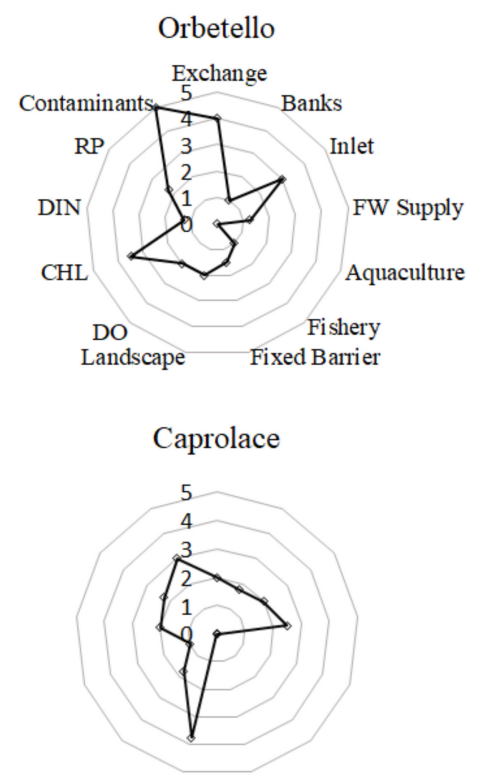

Comacchio

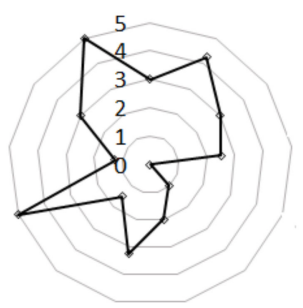

\section{Cabras}

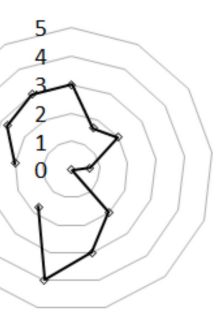

Sabaudia

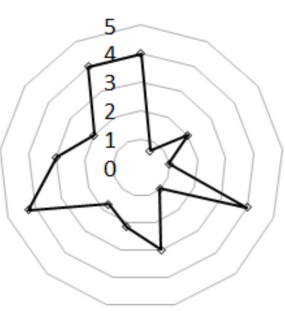

Goro

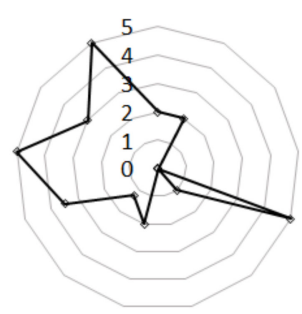

Fogliano

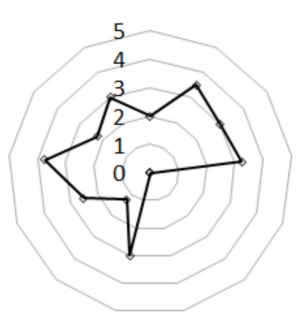

Lesina

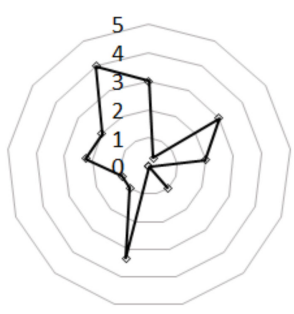

Grado Marano

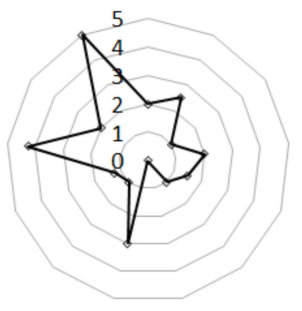

Figure 2. Scores of the anthropogenic pressure indicators for the nine coastal lagoons under study. Scores range between 0 (low pressure) and 5 (high pressure). Vectors represent: Water renewal time (Exchange), Percentage of natural banks (Banks), Status and efficiency of tidal inlets (Inlet), Surface freshwater tributaries (FW Supply), Mussel farming (Aquaculture), Fisheries activities (Fishery), Closed months per year by barriers (Fixed barrier), Percentage of anthropogenically affected land (Landscape), Dissolved Oxygen (DO), Chlorophyll- $a$ (CHL), Dissolved Inorganic Nitrogen (DIN), Reactive Phosphorus (RP), and Contaminants.

The PCA results, in which the first two PCs account for $68 \%$ of the total variation of the dataset, allow to differentiate the nine lagoons based on the relative influence of the 13 pressure indicators. The ordination of the lagoons in the two-dimensional plot (Figure 3) shows SAB, GOR and GRA with positive loadings for the first PC ( $40 \%$ of total variation), associated, among the pressure indicators, to Aquaculture as the leading variable, Dissolved Inorganic Nitrogen and Chlorophyll-a. ORB, COM, CAB, LES, CAP, and FOG share negative loadings for the first PC, associated with pressure indicators belonging to the CPI-Morpho, such as Inlet and Freshwater supply. The second PC (accounting for 28\% of the overall variability) loadings further discriminate these lagoons, in a first group (ORB, $\mathrm{COM}$ and $\mathrm{CAB}$ ) with positive loadings and associated to pressures such as Fixed Barrier and Water Exchange, and a second group (LES, CAP and FOG) with negative loadings and associated to FW Supply, Banks status and Landscape activities. 
Table 3. Environmental assessment of the lagoons under study. Scores of the single pressure indicators, and the Category Pressure Indices (CPIs) with the Final Pressure Index (FPI) of each coastal lagoon are reported, compared with the maximum achievable values. (ORB) Orbetello, (CAB) Cabras, (FOG) Fogliano, (CAP) Caprolace, (SAB) Sabaudia, (LES) Lesina, (COM) Comacchio, (GOR) Sacca di Goro, (GRA) Grado Marano.

\begin{tabular}{|c|c|c|c|c|c|c|c|c|c|}
\hline & ORB & САВ & FOG & CAP & SAB & LES & COM & GOR & GRA \\
\hline Exchange & 4 & 3 & 2 & 2 & 4 & 3 & 3 & 2 & 2 \\
\hline Banks & 1 & 2 & 4 & 2 & 1 & 0 & 4 & 2 & 3 \\
\hline Inlet & 3 & 2 & 3 & 2 & 2 & 3 & 3 & 0 & 1 \\
\hline FW supply & 1 & 1 & 3 & 3 & 1 & 2 & 3 & 0 & 2 \\
\hline CPI-Morpho $(0 / 20)$ & 9 & 8 & 12 & 9 & 8 & 8 & 13 & 4 & 8 \\
\hline Landscape & 2 & 4 & 3 & 4 & 2 & 3 & 3 & 2 & 3 \\
\hline Aquaculture & 0 & 0 & 0 & 0 & 4 & 0 & 0 & 5 & 2 \\
\hline Fishery & 1 & 2 & 0 & 0 & 1 & 1 & 1 & 1 & 1 \\
\hline Fixed Barrier & 2 & 3 & 0 & 0 & 3 & 0 & 2 & 0 & 0 \\
\hline CPI-Use $(0 / 20)$ & 5 & 9 & 3 & 4 & 10 & 4 & 6 & 8 & 6 \\
\hline Dissolved Oxygen & 2 & 2 & 1 & 2 & 2 & 1 & 2 & 1 & 1 \\
\hline Chlorophyll- $a$ & 4 & & 3 & 1 & 4 & 1 & 5 & 4 & 1 \\
\hline Dissolved Inorganic Nitrogen & 1 & 2 & 4 & 2 & 3 & 2 & 1 & 5 & 4 \\
\hline Reactive Phosphorus & 2 & 3 & 2 & 2 & 2 & 2 & 3 & 3 & 2 \\
\hline Contaminants & 5 & 3 & 3 & 3 & 4 & 4 & 5 & 5 & 5 \\
\hline CPI-Qual (0/25) & 14 & 10 & 13 & 10 & 15 & 10 & 16 & 18 & 13 \\
\hline FPI $(0 / 65)$ & 28 & 27 & 28 & 23 & 33 & 22 & 35 & 30 & 27 \\
\hline Level of impact & Medium & Medium & Medium & Low & Medium & Low & Medium & Medium & Medium \\
\hline
\end{tabular}

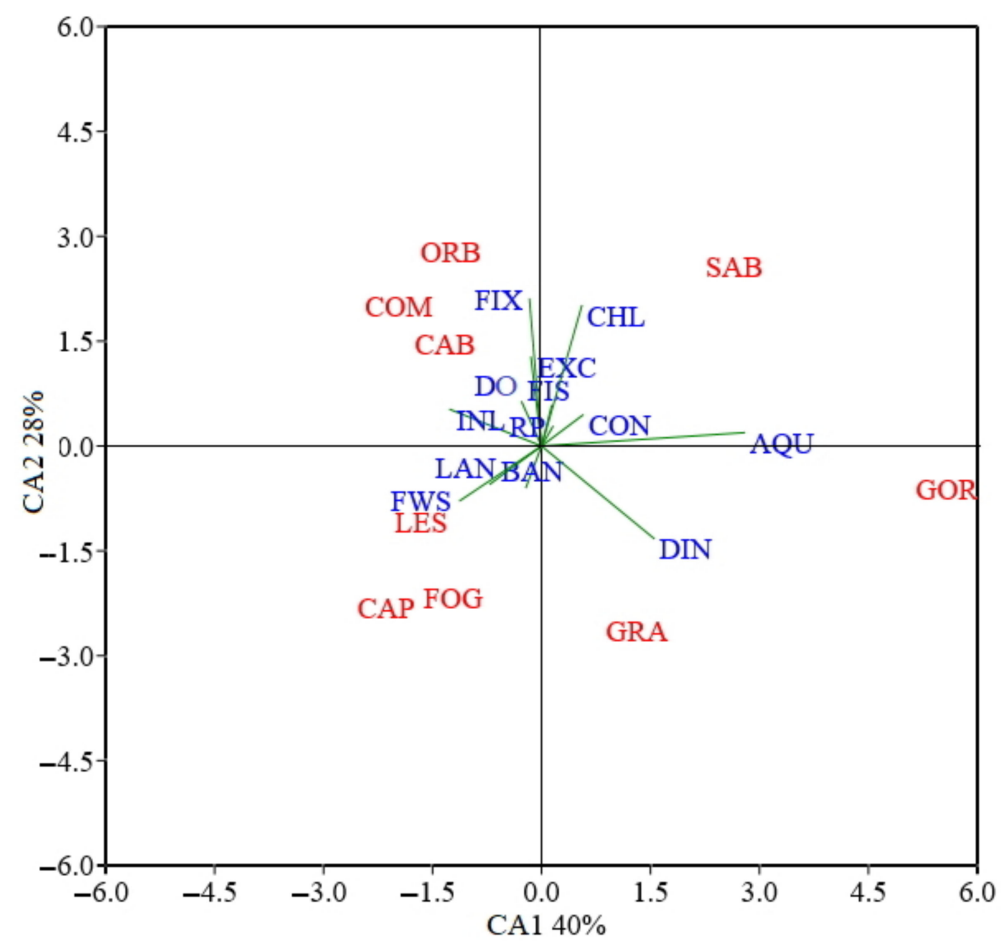

Figure 3. Ordination plot of Principal Component Analysis (PCA) for pressure indicators (blue) in the sites under study (red). Coastal lagoons and vectors for anthropogenic pressures are represented. Pressure indicators: EXC: Exchange, BAN: Banks, INL: Inlet, FWS: Freshwater supply, AQU: Aquaculture, FIS: Fishery, FIX: Fixed barriers, LAN: Landscape, DO: Dissolved Oxygen, CHL: Chlorophyll- $a$, DIN: Dissolved Inorganic Nitrogen, RP: Reactive Phosphorus, CON: Contaminants. Sites: (ORB) Orbetello, (CAB) Cabras, (FOG) Fogliano, (CAP) Caprolace, (SAB) Sabaudia, (LES) Lesina, (COM) Comacchio, (GOR) Sacca di Goro, (GRA) Grado Marano. 


\subsection{Skeletal Anomalies Analysis}

The average SL of fish from all samples was $60( \pm 10.2 \mathrm{SD}) \mathrm{mm}$, ORB samples show the smallest size observed (mean SL $45 \mathrm{~mm}$; range 38-90 mm), and GOR shows the largest size (mean SL $74 \mathrm{~mm}$; range 54-95 mm). Differences in SL among samples were significant for a $p$-value $<0.05$ except for CAB, FOG, SAB, LES, and COM.

All fish from all the lagoons under study presented skeletal anomalies, with $100 \%$ of specimens affected by at least one anomaly except for a single individual in CAP (Table 4). The average anomaly load (average number of anomalies per malformed specimen) ranges between 6 and 19, in the samples from ORB and CAB respectively, with intermediate values in samples from the other sites. No lordosis, kyphosis, deformed jaws and deformed opercular plates were observed. Four sand smelts showed anomalies detectable at an external examination: scoliosis in two fishes (equal to $1.4 \%$ of individuals) from FOG, one $(0.8 \%)$ from CAP and one (1\%) from ORB (See Tables S1 and S2 in Section S2 of Supplementary Materials). Other severe anomalies were partially or totally fused and deformed vertebral centra (Figure 4). Severe anomalies affected a percentage ranging from $1 \%$ (GRA) up to $13 \%$ (COM) of fish in the samples (Table 4). Only three sites (CAP, LES, and GRA) showed less than $6 \%$ of individuals affected by severe anomalies.

Table 4. Metrics from skeletal anomalies analysis in the nine samples of A. boyeri. Sites: (ORB) Orbetello, (CAB) Cabras, (FOG) Fogliano, (CAP) Caprolace, (SAB) Sabaudia, (LES) Lesina, (COM) Comacchio, (GOR) Sacca di Goro, (GRA) Grado Marano.

\begin{tabular}{|c|c|c|c|c|c|c|c|c|c|}
\hline METRIC & ORB & CAB & FOG & CAP & SAB & LES & COM & GOR & GRA \\
\hline Observed individuals $(n)$ & 102 & 116 & 118 & 115 & 102 & 125 & 109 & 139 & 97 \\
\hline Malformed individuals (\%) & 100 & 100 & 100 & 99 & 100 & 100 & 100 & 100 & 100 \\
\hline Average anomaly load for individual & 6 & 19 & 14 & 13 & 17 & 9 & 13 & 14 & 11 \\
\hline Anomalies types (n) & 32 & 44 & 39 & 39 & 41 & 30 & 37 & 34 & 25 \\
\hline Frequency of individual with severe anomalies (\%) & 6 & 8 & 8 & 4 & 6 & 2 & 13 & 6 & 1 \\
\hline Severe anomalies $(\%)$ & 2 & 1 & 1 & 1 & 1 & 0 & 2 & 1 & 0 \\
\hline Average severe anomaly load & 3 & 2 & 2 & 3 & 2 & 1 & 2 & 3 & 2 \\
\hline
\end{tabular}

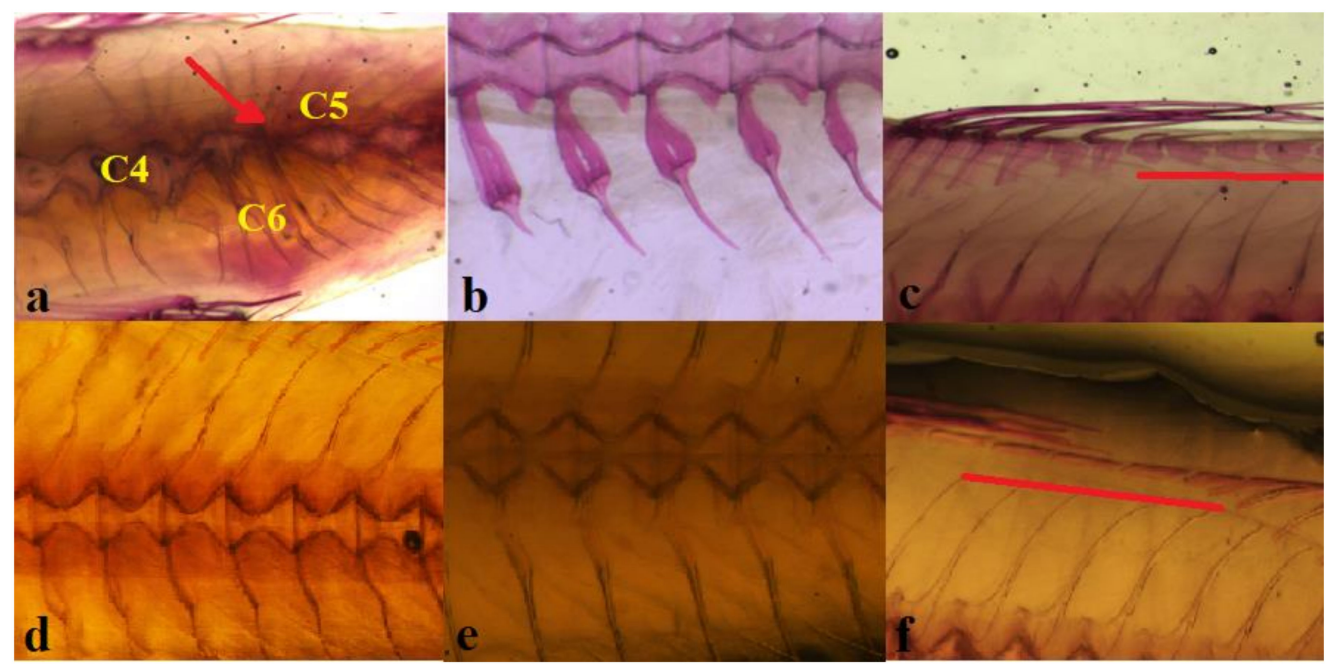

Figure 4. Examples of anomaly types in A. boyeri of three specimens from COM and GOR and normal correspondent structure from ORB, COM and GOR (a) Red arrow points at a multiple vertebrae fusion (C3); C4: malformed vertebral centrum; C5: malformed neural arches and spines; C6: malformed hemal arches and spines (0.8×). (b) Tulip-shaped hemal arches (C6T) in A. boyeri from ORB (1.2×). (c) Anomalous interdorsal skeletal elements (underlined by the red line) in A. boyeri from COM $(1.2 \times)$. (d) Normal vertebral body and neural arches in an ORB specimen $(1.2 \times)$. (e) Normal hemal arches in a COM specimen $(1.2 \times)$. (f) Normal interdorsal elements in a GOR A. boyeri $(1.2 \times)$. 
The number of observed types of anomalies in the different samples ranged between 25 (GRA) and 44 (CAB). The most frequent anomalies were those affecting the hemal arches (viz. C6 and C6T) (Figure 4b) of the hemal vertebrae (GRA: 50\%; LES: 48\%; GOR: 36\%; COM: $33 \%$ of total anomalies). Furthermore, the $13-21 \%$ of the observed anomalies are those affecting the interdorsals (M8*) (Figure 4c) in fish from CAP, FOG, COM, CAB, and SAB. Anomalies involving the epurals (e.g., G10*) and hypurals (e.g., G19) of the caudal fin (range 27-37\% of anomalies), and those affecting abdominal vertebral centra (average 11\%) are observed in all samples (see Tables S1 and S2 in Section S2 of Supplementary Materials).

\subsection{Correspondence Analysis}

A series of CAs have been conducted first on RM (1023 fish $\times 63$ variables), and then on matrices that consider subsets of data. The results of these statistical analyses are illustrated in the Supplementary Materials, Section 2 and Figure 5. The CA performed on the RM (1023 fish $\times 63$ variables, i.e., 62 anomalies and the variable ABS, to take into account specimens devoid of anomalies) gave an ordination model in which $20.7 \%$ of the variance was explained by the first three axes (Figure S1 in Section S2 of Supplementary Materials). Given the low variance obtained by this ordination model and the unclear distributions of the variables (i.e., skeletal anomalies) with respect to the sites of origin, a second CA was performed on a subset of data. The CA was performed on a matrix (1023 specimens and 22 variables, i.e., 21 anomalies and the ABS variable) that were retained, excluding the rarest anomalies (frequency $<4 \%$ in all the specimens) (Figure S2 in Section S2 of Supplementary Materials). This CA gave an ordination model in which $43.4 \%$ of the total variance was explained by the first three axes. Despite the higher explained variance, the ordination model was difficult interpret, because of the weight of the ABS variable, which forces the sites of origin to aggregate close to the origin of the axes.

A further CA performed on the matrix including all fish (1022 in total, the single specimens without any anomalies being excluded) and 21 anomalies (all the anomalies except the rarest) gave an ordination model in which $30 \%$ of the total variance was explained by the first three axes. The obtained ordination model fairly discriminates the sites based on the 21 types of skeletal anomalies represented in the corresponding fish samples. In Figure 5 the ordination model on the first two correspondences axes (i.e., CA1 and CA2) is shown. The samples from the COM, GOR, GRA, LES, and ORB lagoons are arranged in the negative space of CA1, in association with anomalies such as supernumerary arches of hemal vertebrae (D5* D6*), deformed hemal arches of abdominal and hemal vertebrae (B6, C6T), hypural with demineralization (G19) and hypermineralized or deformed epurals (G10, G10*). CAB, CAP, FOG and SAB samples plot in the positive space of CA1, in association with pterygiophore anomalies of anal and dorsal fins (F8, H8 and I8), hypermineralized hypurals (G19*), deformations of hemal arches of hemal (C6) and caudal vertebrae (D6). Malformed zygapophysis of abdominal vertebrae (B4z), malformed neural arches or spine of abdominal vertebrae (B5), tulip-like shaped hemal arches of the hemal vertebrae (C6T), malformed left pectoral fin rays (E11L), malformed caudal fin rays (G11), and malformed interdorsal element (M8*) were the anomalies providing the highest absolute contributions and therefore retained for further analysis (Figure S3 in Section S2 of Supplementary Materials).

\subsection{Multiple Correspondence Analysis (MCA)}

In order to highlight potential relationships among type of anomalies, sites and anthropogenic pressures, an MCA was carried out. The MCA returned a cumulative explained inertia for the first two dimensions amounting to $38 \%$. Therefore, a two-dimensions MCA solution was considered the most adequate. The results are shown in Figure $6 \mathrm{a}-\mathrm{C}$, separately for each categorical variable. 


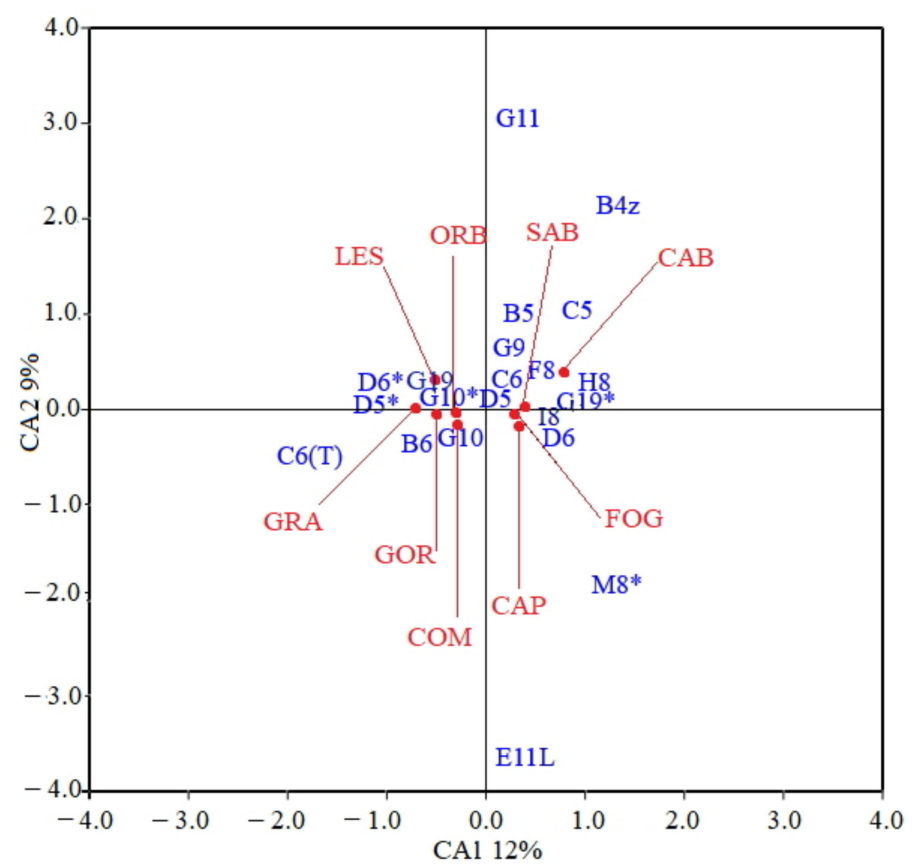

Figure 5. Correspondence analysis (CA), ordination of samples in the first two factorial axes (CA1 and CA2) plane. These axes account for $21 \%$ of total variance. Skeletal anomalies: malformed zygapophysis of abdominal vertebrae (B4z), malformed neural and hemal elements associated to abdominal vertebrae (B5, B6), malformed neural and hemal elements associated to hemal vertebrae (C5, C6), tulip-like shaped hemal arch of hemal vertebrae (C6T), malformed neural and hemal elements associated to caudal vertebrae (D5, D6), supernumerary neural and hemal elements associated to caudal vertebrae $\left(\mathrm{D} 5^{*}, \mathrm{D} 6^{*}\right)$, malformed rays of left pectoral fin (E11L), malformed pterygiophore of the anal fin (F8), malformed hypural (G9), malformed or hypermineralized epural (G10, G10*), malformed caudal fin rays (G11), hypural with demineralization (G19), hypermineralized hypural $\left(\mathrm{G} 19^{*}\right)$, malformed pterygiophore of the first and second dorsal fin (H8, I8), malformed interdorsal elements. Sites: (ORB) Orbetello, (CAB) Cabras, (FOG) Fogliano, (CAP) Caprolace, (SAB) Sabaudia, (LES) Lesina, (COM) Comacchio, (GOR) Sacca di Goro, (GRA) Grado Marano.

A comparison of plots for the two variables, relative to anomalies types (Figure 6a) and site origin (Figure 6b) evidence along Dimension1 two groups for each variable: one is for negative values of Dim1, with anomaly C6T and sites LES, GRA, and GOR, and one is for positive values (all the other sites, and the other anomalies). Along Dimension2, E11L, B5, B4z, and M8 locate in the same quadrant of ORB, SAB, and CAB; C6T plot in the negative semi-axis of both Dim1 and Dim2, together with GRA and LES. The site GOR plots in the second quadrant, and the sites COM, CAP, and FOG, along with G11, plot in the fourth quadrant.

Figure $6 \mathrm{c}$ shows the plot of the variables relative to anthropogenic pressure indicators, whose position can be compared with the plot relative to the "site of origin" (Figure 6b). Indicators (Figure 6c) related to the category of land and resources use (CPI-Use), such as Fixed barrier/3 (FIX3), Fishery / 1 (FIS1), and SAB and CAB among sites (Figure 6b) are driven by positive values of Dimension1. The indicators related to Water quality (CPI-Qual): Dissolved Oxygen/2 (DO2) and Reactive Phosphorus/3 (RP3), associated to ORB as a site of origin, plot for lower positive values of Dim1. In an adjacent position but for negative values of Dim2, indicators related to water quality plot, such as Contaminants/3 (CON3), Dissolved Inorganic Nitrogen/3, and to resources use (CPI-Use), such as Landscape/4 (LAN4), with CAP., COM and FOG similarly positioned among sites. 

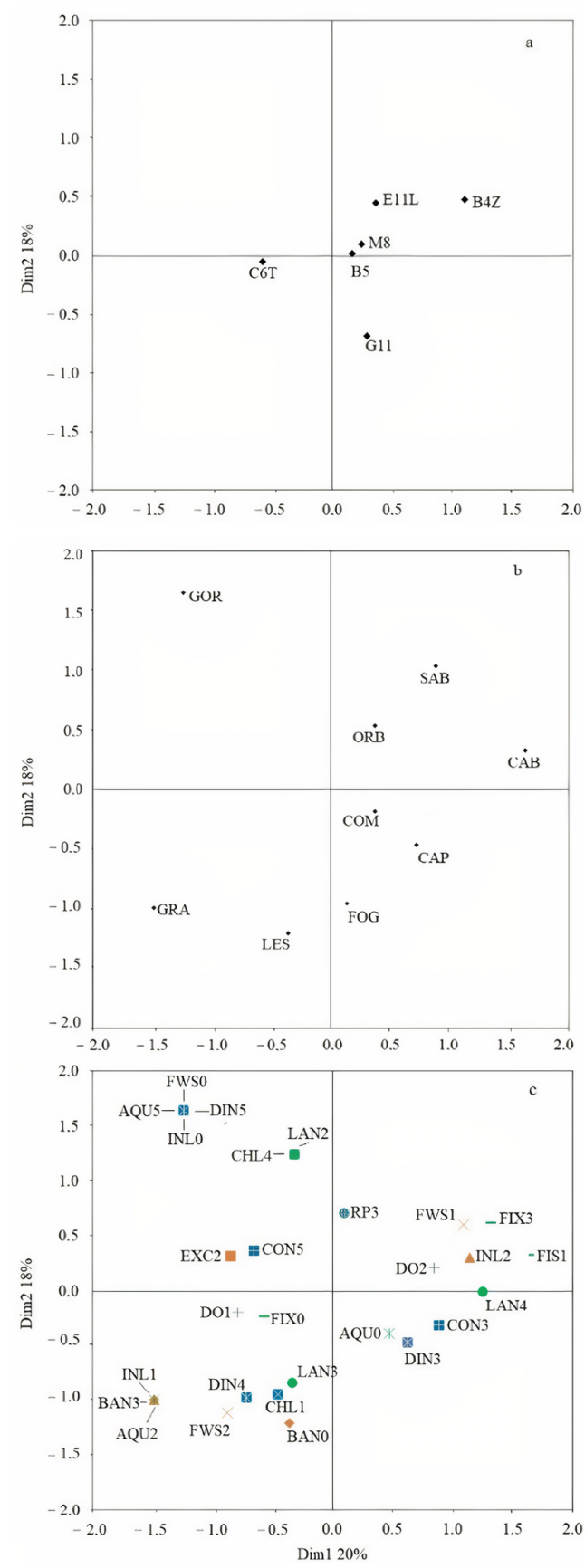

Figure 6. Multiple Correspondence Analysis (MCA): plots of the categorical variables considered. Active variables: skeletal anomalies (a) and anthropogenic pressures (c); supplementary variable: sites (b) (the supplementary variable is shown as the central plot to facilitate the interpretation of the results). (a) Skeletal anomalies: malformed zygapophysis of abdominal vertebrae (B4z), malformed neural arches or spine of abdominal vertebrae (B5), Tulip-like shaped hemal arches of the hemal vertebrae (C6T), malformed left pectoral fin rays (E11L), malformed caudal fin rays (G11), and malformed interdorsal element (M8). (b) Sites: (ORB) Orbetello, (CAB) Cabras, (FOG) Fogliano, (CAP) Caprolace, (SAB) Sabaudia, (LES) Lesina, (COM) Comacchio, (GOR) Sacca di Goro, (GRA) Grado Marano. (c) Anthropogenic pressures: (EXC) Exchange, (BAN) Banks, (INL) Inlet, (FWS) Freshwater supply, (AQU) Aquaculture, (FIS) Fishery, (FIX) Fixed barriers, (LAN) Landscape, (DO) Dissolved Oxygen, (CHL) Chlorophyll- $a$, (DIN) Dissolved Inorganic Nitrogen, (RP) Reactive Phosphorus, (CON) Contaminants. The numbers in the labels represent the relative score (from 0 to 5) of the specific anthropogenic pressure indicator. Only the variables with cumulative explained inertia $>1 \%$ are plotted. 
A second group of category variables plots for positive values of Dim2: and negative values of Dim1: it includes among pressure indicators (Figure 6c), those belonging to the CPI-Qual, in particular, Contaminants, Chlorophyll and Dissolved Inorganic Nitrogen with high scores (CON5, CHL4; DIN5) and, among CPI-Use, Aquaculture (AQU5), along with the site GOR. A third group, for negative values of the two Dimensions, brings together variables relative to pressure indicators of all categories presenting intermediate scores, as well as GRA and LES among the sites (Figure 6b).

\section{Discussion}

In this study, the skeletal condition of $A$. boyeri complex was examined in populations from nine Mediterranean coastal lagoons along the coasts of Italy. The study sites differ in typology, ecological features, and management frameworks. The lagoons' quality status was also evaluated based on several environmental descriptors of direct and indirect human pressures acting on the ecosystems. The results allow for some considerations on different aspects, which are discussed in relation to all the available studies on skeletal anomalies in coastal lagoons wild fish.

A first, unexpected, result is that all $A$. boyeri from all sites presented at least one skeletal anomaly, with only one specimen (from CAP) free of any anomaly. This investigation on skeletal anomalies in big-scale sand smelt has been carried out following the same approach used in a previous study on wild juveniles of three Mugilid species from three sites, two of which were Goro and Lesina [57]. In that study, $16 \%$ of juvenile mullet (on a total of 873 juveniles) had at least one skeletal anomaly in Goro, and 15\% (on a total of 910) in Lesina. In both lagoons, the same frequency of juvenile fish with severe anomalies $(12 \%)$ was found, but a higher anomaly load was observed in mullets from Goro (5.3) with respect to those from Lesina (1.9). In the present investigation, carried out with the same methodology but targeting a resident species at the adult stage, sand smelts from Goro showed a worse general condition as well with regard to skeletal anomalies than fish from Lesina, as shown by the average anomaly load (14 vs. 9), the number of anomalies types ( $34 \mathrm{vs} .30)$, the occurrence of severely deformed fish ( $6 \%$ vs. $2 \%)$, the frequency of severe anomalies ( $1 \%$ vs. $0 \%$ ) and severe anomaly load ( 2 vs. 1 ). In juvenile mullets, severe anomalies such as those affecting jaw and opercular plate, kyphosis, and lordosis were detected [57], while none of these anomalies was found in adult sand smelt from any of sites considered in the present study.

Differences in skeletal anomalies frequencies (both in total and considering only severe anomalies) and in the skeletal anomaly patterns detected in different species dwelling in coastal lagoons, i.e., three Mullet species [57] and the A. boyeri complex (present study), could be ascribed to the different life stages under examination: mullets were all early juveniles while sand smelt were adults. Morphological anomalies are usually rare in natural fish populations, especially in adult fish, because depending on the severity of the anomaly, larvae and juveniles are progressively eliminated from the population due to natural mortality, predation, and competition [29].

Although $100 \%$ of sand smelts in almost all sites object of this study were affected by skeletal anomalies, some of them were very rare (affecting $\leq 4 \%$ of the total fish) or extremely common (affecting $\geq 75 \%$ of total fish). Only one anomaly (G19) was present in the $75 \%$ of the total fish analyzed (considered as background noise), while the other 41 affected very few individuals ( $\leq 4 \%$ of total fish). However, only four sand smelts showed anomalies detectable at an external examination: scoliosis in two fish (equal to $1.4 \%$ of individuals) from FOG, one ( $0.8 \%$ ) from CAP and one (1\%) from ORB.

Such anomalies can be expected in fish species living in fluctuating environments which vary consistently over space and time [1,3], especially in adult big-scale sand smelt, a species with high morphological variability and plasticity $[3,8,73,74]$, and elevate phenotypic polymorphism $[10,11]$. On the other hand, some metrics, such as the average anomaly load of anomalies and the frequency of individuals with severe anomalies, allowed us to discriminate samples based on the lagoons of origin. 
The comparison with published surveys carried out on sand smelt in other sites evidenced the presence of lordosis and/or scoliosis affecting the $3.6 \%$ of 1479 sand smelts from the Nerevta river estuary, in the middle Adriatic [59], a single specimen found in the Homa Lagoon, Turkey [60], and 9.7\% of 2175 A. lagunae from the Tunis North Lake [58]. All these sites are described as heavily polluted. The absence of lordosis and kyphosis in big-scale sand smelts from the nine lagoons surveyed in this study is then in line with the results achieved with the environmental assessment, that highlight that in all the study sites the anthropogenic impact is of medium level, and with the fact that in none of the study sites severe specific pollution is reported. Many authors have hypothesized a relationship between skeletal anomalies in fish living in degraded ecosystems and environmental conditions [47,50,53-57]. Anomalies are taken into account in the IBI [51], which incorporates DELT anomalies (including skeletal deformities), and returns a classification of good environmental status for a water body if less than the $2 \%$ of examined fish is affected, degraded if the frequency ranges between 2 and $5 \%$, and heavily degraded if it exceeds the $5 \%$. Following this approach, and considering only the severe anomalies in fish, the lagoons of COM, ORB, CAB, FOG, GOR, and SAB should be considered heavily degraded. The severe anomalies were the above mentioned scoliosis and fusions (total or partial) and deformations of the vertebral centra, that contributed to the scores of some general metrics (i.e., frequency of individual with severe anomalies; frequency of severe anomalies; average severe anomaly load). Therefore, the absence of spinal deformations, and the presence of severe anomalies, give a partially contradictory evaluation. More in-depth analyses, based on larger samples from a larger number of sites, would be needed to settle the issue.

However, based on results of the present study and taking into account the twosummary metrics related to skeletal anomalies in fish samples, i.e., the frequency of individuals with severe anomalies and the average individual anomaly load, the former better evidence a relationship with the lagoon overall quality status as evaluated by the expert judgement approach applied in this study. Based on the type and severity of the anthropogenic pressures acting on the nine lagoons under study, in most of them, a medium level of anthropogenic impact was highlighted, with different scores of the Final Pressure Index (higher in GOR, COM, SAB and lower in others: GRA, ORB, FOG, CAB), and only two (CAP and LES) were less exposed to anthropogenic impacts. Accordingly, lagoons with higher FPI values show higher frequencies of severely affected individuals. On the reverse, the less impacted lagoons show lower frequencies of individuals affected by severe anomalies (LES). An exception is GRA, which also shows a low frequency of individuals with severe anomalies, albeit showing a medium level of anthropogenic impact. The average individual load of anomalies seems less representative, showing lower values only in LES and ORB fish.

Some conclusive remarks can be made on the basis of results attained in the present study. With some distinctions, the results obtained with the two different approaches, one based on the assessment of lagoons quality status using anthropogenic pressure indicators and the other which considers the morphological analysis of the skeletal malformations of a resident fish species, return two similar evaluations for the nine coastal lagoons taken into consideration.

The analysis of skeletal anomalies in A. boyeri complex from nine Mediterranean coastal lagoons has allowed us to describe in detail anomalies and their occurrence in this lagoon-resident fish. The skeletal anomalies monitoring in big-scale sand smelt evidenced some potentiality as a tool for early detection of anthropogenic impacts if some overall metrics and specific anomalies are taken into consideration. Some typical anomalies characterize big-scale sand smelt from individual lagoons, while the frequency of individuals with severe anomalies and the average individual anomaly load allowed us discriminate among fish from different coastal lagoons and other anthropogenic impacts. 
Supplementary Materials: The following are available online at https://www.mdpi.com/2073 $-4441 / 13 / 2 / 159 / s 1$, The following Supplementary Material contains additional information to $\mathrm{MM}$ and Results sections and is organized in two sections: Section S1. Environmental quality assessment; S2. Skeletal anomalies. Section S1. Environmental quality assessment. Table S1. Single pressure indicators that contribute to three categories of anthropogenic pressures. Table S2. Pressure indicators, description and degree levels of change (impact score) proposed for the quantification of the anthropogenic pressures. Section S2. Skeletal anomalies. Table S1. Frequencies (\%) of individual affected by each anomaly. Table S2. Frequencies (\%) of each type of anomaly on the total number of anomalies. Figure S1. Correspondence analysis (1023 fish x 63 variables). Figure S2. Correspondence analysis (1023 specimens and 22 variables). Figure S3. R output for the analysis of the variable contribution for the matrix $1022 \times 2$.

Author Contributions: Conceptualization C.L., E.C. and C.B.; methodology for skeletal analysis C.B.; methodology for environmental status assessment, C.L. and E.C.; software, F.D.L.; validation, F.D.L., C.L. and C.B.; formal analysis, F.D.L.; investigation, F.D.L.; data curation, F.D.L., C.L., E.C. and C.B.; writing - original draft preparation, C.L. and F.D.L.; writing—review and editing, E.C., A.M. and C.B.; supervision, E.C. and C.B.; project administration, E.C. All authors have read and agreed to the published version of the manuscript.

Funding: This research was funded by Italian Ministry of Agricultural Food and Forestry Policy within the Research Project LAGURES (grant n. J88C13001250001).

Institutional Review Board Statement: Ethics approval was not required for this study.

Informed Consent Statement: Not applicable.

Data Availability Statement: Data is contained within the article and its supplementary material.

Acknowledgments: This work was supported by the Italian Ministry of Agricultural, Food and Forestry Policy within the Research Project LAGURES (grant n. J88C13001250001) under the scientific supervision of E.C. The authors acknowledge the support of Massimo Cecchetti and Andrea Fusari during samplings carried out at the Circeo lagoons and Lesina, and Mattia Lanzoni, Alessandra Cannas and Michele Pellizzato for providing fish samples from Comacchio and Goro, Cabras and Grado Marano, respectively. A special thanks to Valeria Seno and Chiara Pittoni for the fish skeletal analysis and to Marco Martinoli and Silvio Marta for the data relative the Corine Land Cover. The authors also acknowledge the Regional Administrative Offices of Environment (ARPAs) for sharing data and final reports related to the monitoring foreseen under the MD 260/2010 e Lgs.D 172/2015.

Conflicts of Interest: The authors declare no conflict of interest.

\section{References}

1. Kara, M.H.; Quignard, J.P. Atherinidea. In Fishes in Lagoons and Estuaries in the Mediterranean: Diversity, Bioecology and Exploitation; Ecological Science Series; John Wiley \& Sons, Inc.: Hoboken, NJ, USA, 2018; Volume 2, pp. 1-48.

2. Mistri, M.; Colombo, G. Morphometric variability in sandsmelt, Atherina boyeri Risso 1810, populations from different italian sites. Ital. J. Zool. 1988, 55, 129-132. [CrossRef]

3. Bamber, R.N.; Henderson, P.A. Pre-adaptive plasticity. J. Fish Biol. 1988, 33, 17-23. [CrossRef]

4. Antonucci, F.; Boglione, C.; Cerasari, V.; Caccia, E.; Costa, C. External shape analyses in Atherina boyeri (Risso, 1810) from different environments. Ital. J. Zool. 2012, 79, 60-68. [CrossRef]

5. Quignard, J.P.; Pras, A. Atherinidae. In Fishes of the North-Eastern Atlantic and Mediterranean (FNAM); Whitehead, P.J.P., Bauchot, M.-L., Hureau, J.-C., Nielsen, J.T.E., Eds.; UNESCO: Paris, France, 1986; pp. 1207-1210.

6. Fishbase: Big Scale sand Smelt Atherina boyeri (Risso, 1810). Available online: https://www.fishbase.se/summary/1696 (accessed on 20 January 2020).

7. Bartulović, V.; Glamuzina, B.; Conides, A.; Dulčić, J.; Lučić, D.; Njire, J.; Kožul, V. Age, growth, mortality and sex ratio of sand smelt, Atherina boyeri Risso, 1810 (Pisces: Atherinidae) in the estuary of the Mala Neretva River (middle-eastern Adriatic, Croatia). J. Appl. Ichthyol. 2004, 20, 427-430. [CrossRef]

8. Kiener, A.; Spillmann, C.J. Contribution à l'étude systématique et écologique des Athérines des côtes françaises. Mem. Mus. Natl. d'Histoire Nat. 1969, 60, 33-74.

9. Francisco, S.M.; Congiu, L.; Stefanni, S.; Castilho, R.; Brito, A.; Ivanova, P.P.; Levy, A.; Cabral, H.; Kilias, G.; Doadrio, I. Phylogenetic relationships of the North-eastern Atlantic and Mediterranean forms of Atherina (Pisces, Atherinidae). Mol. Phylogenet. Evol. 2008, 48, 782-788. [CrossRef] [PubMed] 
10. Focant, B.; Rosecchi, E.; Crivelli, A.J. Attempt at biochemical characterization of sand smelt Atherina boyeri Risso, 1810 (Pisces, Atherinidae) populations from the Camargue (Rhône delta, France). Comp. Biochem. Physiol. Part B Biochem. Mol. Biol. 1999, 122, 261-267. [CrossRef]

11. Astolfi, L.; Dupanloup, I.; Rossi, R.; Bisol, P.M.; Faure, E.; Congiu, L. Mitochondrial variability of sand smelt Atherina boyeri populations from north Mediterranean coastal lagoons. Mar. Ecol. Prog. Ser. 2005, 297, 233-243. [CrossRef]

12. Trabelsi, M.; Gilles, A.; Fleury, C.; Mâamouri, F.; Quignard, J.P.; Faure, É. Atherina punctata and Atherina lagunae (Pisces, Atherinidae), new species found in the Mediterranean Sea. 1.Biometric investigations of three Atherinid species. C.R.-Biol. 2002, 325, 967-975. [CrossRef]

13. Trabelsi, M.; Gilles, A.; Fleury, C.; Mâamouri, F.; Quignard, J.P.; Faure, É. Atherina punctata and Atherina lagunae (Pisces, Atherinidae), new species found in the Mediterranean Sea. 2. Molecular investigations of three Atherinid species. C.R.-Biol. 2002, 325, 1119-1128. [CrossRef]

14. Avise, J.C.; Wollenberg, K. Phylogenetics and the origin of species. Proc. Natl. Acad. Sci. USA 1997, 94, 7748-7755. [CrossRef] [PubMed]

15. Gilliers, C.; Amara, R.; Bergeron, J.P. Comparison of growth and condition indices of juvenile flatfish in different coastal nursery grounds. Environ. Biol. Fishes 2004, 71, 189-198. [CrossRef]

16. Trabelsi, M.; Bourigat, N.; Aurelle, D.; Quignard, J.-P.; Barthelemy, R.; Faure, E. Some Marine Tunisian Atherina boyeri Populations (Teleostei) have Morphological and Molecular Characteristics of Lagoon Fishes. Open Mar. Biol. J. 2009, 3, 59-69. [CrossRef]

17. Serrano Gordo, L.; Nogueira Cabral, H. The fish assemblage structure of a hydrologically altered coastal lagoon: The Óbidos lagoon (Portugal). Hydrobiologia 2001, 459, 125-133. [CrossRef]

18. Franco, A.; Franzoi, P.; Malavasi, S.; Riccato, F.; Torricelli, P.; Mainardi, D. Use of shallow water habitats by fish assemblages in a Mediterranean coastal lagoon. Estuar. Coast. Shelf Sci. 2006, 66, 67-83. [CrossRef]

19. Kapetsky, J.M.; Lasserre, G. Management of Coastal Lagoon Fisheries. Stud. Rev. 1984, 61, 439-776.

20. Pérez-Ruzafa, A.; Marcos, C.; Pérez-Ruzafa, I.M.; Barcala, E.; Hegazi, M.I.; Quispe, J. Detecting changes resulting from human pressure in a naturally quick-changing and heterogeneous environment: Spatial and temporal scales of variability in coastal lagoons. Estuar. Coast. Shelf Sci. 2007, 75, 175-188. [CrossRef]

21. Pérez-Ruzafa, A.; Pérez-Ruzafa, I.M.; Newton, A.; Marcos, C. Coastal Lagoons: Environmental Variability, Ecosystem Complexity, and Goods and Services Uniformity. In Coasts and Estuaries; Elsevier: Amsterdam, The Netherlands, $2019 ;$ pp. $253-276$.

22. Costanza, R.; D’Arge, R.; de Groot, R.; Farber, S.; Grasso, M.; Hannon, B.; Limburg, K.; Naeem, S.; O’Neill, R.V.; Paruelo, J.; et al. The value of the world's ecosystem services and natural capital. Nature 1997, 387, 253-260. [CrossRef]

23. Barbier, E.B.; Hacker, S.D.; Kennedy, C.; Koch, E.W.; Stier, A.C.; Silliman, B.R. The value of estuarine and coastal ecosystem services. Ecol. Monogr. 2011, 81, 169-193. [CrossRef]

24. Newton, A.; Brito, A.C.; Icely, J.D.; Derolez, V.; Clara, I.; Angus, S.; Schernewski, G.; Inácio, M.; Lillebø, A.I.; Sousa, A.I. Assessing, quantifying and valuing the ecosystem services of coastal lagoons. J. Nat. Conserv. 2018, 44, 50-65. [CrossRef]

25. Velasco, A.M.; Pérez-Ruzafa, A.; Martínez-Paz, J.M.; Marcos, C. Ecosystem services and main environmental risks in a coastal lagoon (Mar Menor, Murcia, SE Spain): The public perception. J. Nat. Conserv. 2018, 43, 180-189. [CrossRef]

26. Elliott, M.; Burdon, D.; Hemingway, K.L.; Apitz, S.E. Estuarine, coastal and marine ecosystem restoration: Confusing management and science-A revision of concepts. Estuar. Coast. Shelf Sci. 2007, 74, 349-366. [CrossRef]

27. Elliott, M.; Day, J.W.; Ramachandran, R.; Wolanski, E. A synthesis: What is the future for coasts, estuaries, deltas and other transitional habitats in 2050 and beyond? In Coasts and Estuaries; Elsevier: Amsterdam, The Netherlands, $2019 ;$ pp. 1-28.

28. Newton, A.; Icely, J.; Cristina, S.; Brito, A.; Cardoso, A.C.; Colijn, F.; Riva, S.D.; Gertz, F.; Hansen, J.W.; Holmer, M. An overview of ecological status, vulnerability and future perspectives of European large shallow, semi-enclosed coastal systems, lagoons and transitional waters. Estuar. Coast. Shelf Sci. 2014, 140, 95-122. [CrossRef]

29. Chovanec, A.; Hofer, R.; Schiemer, F. Chapter 18 Fish as bioindicators. In Trace Metals and Other Contaminants in the Environment; Elsevier: Amsterdam, The Netherlands, 2003; pp. 639-676.

30. Kane, A.S.; Salierno, J.D.; Brewer, S.K. Fish models in behavioral toxicology: Automated techniques, updates and perspectives. Methods Aquat. Toxicol. 2005, 2, 1-38.

31. Pont, D.; Hugueny, B.; Beier, U.; Goffaux, D.; Melcher, A.; Noble, R.; Rogers, C.; Roset, N.; Schmuz, S. Assessing river biotic condition at a continental scale: A European approach using functional metrics and fish assemblages. J. Appl. Ecol. 2006, 43, 70-80. [CrossRef]

32. Kuklina, I.; Kouba, A.; Kozák, P. Real-time monitoring of water quality using fish and crayfish as bio-indicators: A review. Environ. Monit. Assess. 2013, 185, 5043-5053. [CrossRef]

33. Shedd, T.R.; van der Schalie, W.H.; Widder, M.W.; Burton, D.T.; Burrows, E.P. Long-Term Operation of an Automated Fish Biomonitoring System for Continuous Effluent Acute Toxicity Surveillance. Bull. Environ. Contam. Toxicol. 2001, 66, 392-399. [CrossRef]

34. Scardi, M.; Tancioni, L.; Cataudella, S. Monitoring methods based on fish. In Biological Monitoring of Rivers; Wiley: Hoboken, NJ, USA, 2006; pp. 135-153.

35. Elas, J.; Lopez-Lopez, E. Freshwater Fish as Sentinel Organisms: From the Molecular to the Population Level, a Review. In New Advances and Contributions to Fish Biology; In Tech: London, UK, 2012. 
36. Facca, C.; Cavraro, F.; Franzoi, P.; Malavasi, S. Lagoon resident fish species of conservation interest according to the habitat directive (92/43/CEE): A review on their potential use as ecological indicator species. Water 2020, 12, 2059. [CrossRef]

37. European Council Directive. European Commission Directive 2000/60/EC of the European Parliament and of the Council of 23 October 2000 Establishing a Framework for Community Action in the Field of Water Policy. Off. J. Eur. Communities 2000, $327,1-72$.

38. Pérez-Domínguez, R.; Maci, S.; Courrat, A.; Lepage, M.; Borja, A.; Uriarte, A.; Neto, J.M.; Cabral, H.; St. Raykov, V.; Franco, A. Current developments on fish-based indices to assess ecological-quality status of estuaries and lagoons. Ecol. Indic. 2012, 23, 34-45. [CrossRef]

39. Pasquaud, S.; Courrat, A.; Fonseca, V.F.; Gamito, R.; Gonçalves, C.I.; Lobry, J.; Lepage, M.; Costa, M.J.; Cabral, H. Strength and time lag of relationships between human pressures and fish-based metrics used to assess ecological quality of estuarine systems. Estuar. Coast. Shelf Sci. 2013, 134, 119-127. [CrossRef]

40. Souza, G.B.G.; Vianna, M. Fish-based indices for assessing ecological quality and biotic integrity in transitional waters: A systematic review. Ecol. Indic. 2020, 109, 105665. [CrossRef]

41. Uriarte, A.; Borja, A. Assessing fish quality status in transitional waters, within the European Water Framework Directive: Setting boundary classes and responding to anthropogenic pressures. Estuar. Coast. Shelf Sci. 2009, 82, 214-224. [CrossRef]

42. Teichert, N.; Borja, A.; Chust, G.; Uriarte, A.; Lepage, M. Restoring fish ecological quality in estuaries: Implication of interactive and cumulative effects among anthropogenic stressors. Sci. Total Environ. 2016, 542, 383-393. [CrossRef]

43. Cavraro, F.; Bettoso, N.; Zucchetta, M.; D'Aietti, A.; Faresi, L.; Franzoi, P. Body condition in fish as a tool to detect the effects of anthropogenic pressures in transitional waters. Aquat. Ecol. 2019, 53, 21-35. [CrossRef]

44. Zucchetta, M.; Scapin, L.; Cavraro, F.; Pranovi, F.; Franco, A.; Franzoi, P. Can the Effects of Anthropogenic Pressures and Environmental Variability on Nekton Fauna Be Detected in Fishery Data? Insights from the Monitoring of the Artisanal Fishery within the Venice Lagoon. Estuaries Coasts 2016, 39, 1164-1182. [CrossRef]

45. Cavraro, F.; Zucchetta, M.; Malavasi, S.; Franzoi, P. Small creeks in a big lagoon: The importance of marginal habitats for fish populations. Ecol. Eng. 2017, 99, 228-237. [CrossRef]

46. Tancioni, L.; Scardi, M.; Cataudella, S. I pesci nella valutazione dello stato ecologico dei sistemi acquatici. Ann. Ist. Super. Sanita 2005, 41, 399-402.

47. Dahlberg, M.D. Frequencies of Abnormalities in Georgia Estuarine Fishes. Trans. Am. Fish. Soc. 1970, 99, 95-97. [CrossRef]

48. Daoulas, C.; Economou, A.N.; Bantavas, I. Osteological abnormalities in laboratory reared sea-bass (Dicentrarchus labrax) fingerlings. Aquaculture 1991, 97, 169-180. [CrossRef]

49. Da Cunha, P.L.; Antunes, M.M. Occurrence of vertebral deformities in Gobiidae (Pisces) from the Tagus estuary. Aquat. Ecol. 1999, 33, 281-285. [CrossRef]

50. Karr, J.R. Assessment of Biotic Integrity Using Fish Communities. Fish. Mag. 1981, 6, 21-27. [CrossRef]

51. Karr, J.R.; Fausch, K.D.; Angermeier, P.L.; Yant, P.R.; Schlosser, I.J. Assessing biological integrity in running waters: A method and its rationale. Ill. Nat. Hist. Surv. Spec. Publ. 1986, 5, 1-28.

52. Hall, B.K.; Witten, P. Plasticity and variation of skeletal cells and tissues and the evolutionary development of Actinopterygian fishes. In Evolution and Development of Fishes; Cambridge University Press: Cambridge, UK, 2018; pp. 126-143.

53. Bengtsson, B.-E.; Bengtsson, A.; Tjornlund, U. Effects of pulp mill effluents on vertebrae of fourhorn sculpin, Myoxocephalus quadricornis, bleak, Alburnus alburnus, and perch, Perca fluviatilis. Arch. Environ. Contam. Toxicol. 1988, 17, 789-797. [CrossRef]

54. Kirchhoff, S.; Sévigny, J.-M.; Couillard, C.M. Genetic and meristic variations in the mummichog Fundulus heteroclitus, living in polluted and reference estuaries. Mar. Environ. Res. 1999, 47, 261-283. [CrossRef]

55. Slooff, W. Skeletal anomalies in fish from polluted surface waters. Aquat. Toxicol. 1982, 2, 157-173. [CrossRef]

56. Villeneuve, D.L.; Curtis, L.R.; Jenkins, J.J.; Warner, K.E.; Tilton, F.; Kent, M.L.; Watral, V.G.; Cunningham, M.E.; Markle, D.F.; Sethajintanin, D.; et al. Environmental Stresses and Skeletal Deformities in Fish from the Willamette River, Oregon. Environ. Sci. Technol. 2005, 39, 3495-3506. [CrossRef]

57. Boglione, C.; Costa, C.; Giganti, M.; Cecchetti, M.; Di Dato, P.; Scardi, M.; Cataudella, S. Biological monitoring of wild thicklip grey mullet (Chelon labrosus), golden grey mullet (Liza aurata), thinlip mullet (Liza ramada) and flathead mullet (Mugil cephalus) (Pisces: Mugilidae) from different Adriatic sites: Meristic counts and skeletal anomalies. Ecol. Indic. 2006, 6, 712-732. [CrossRef]

58. Ayed, N.; Faure, E.; Quignard, J.-P.; Maamouri, F.; Trabelsi, M. Incidence of kyphosis deformities in natural population of Atherina lagunae (Trabelsi et al., 2002) from the Tunis North Lake, Tunisia. Mar. Biol. 2008, 153, 319-325. [CrossRef]

59. Tutman, P.; Glamuzina, B.; Skaramuca, B.; Kožul, V.; Glavić, N.; Lučić, D. Incidence of spinal deformities in natural populations of sandsmelt, Atherina boyeri (Risso, 1810) in the Neretva river estuary, middle Adriatic. Fish. Res. 2000, 45, 61-64. [CrossRef]

60. Jawad, L.; Akyol, O.; Sağlam, C. Consecutive repetition of lordosis-kyphosis in silverside Atherina boyeri Risso, 1810 collected from a wild population in Homa Lagoon, Izmir, Turkey. Arch. Pol. Fish. 2017, 25, 117-122. [CrossRef]

61. Leonardos, I.; Sinis, A.; Petridis, D. Influence of environmental factors on the population dynamics of Aphanius fasciatus (Nardo 1827) (Pisces: Cyprinodontidae) in the Lagoons Messolongi and Etolikon (W. Greece) No Title. Isr. J. Ecol. Evol. 1996, 42, $231-249$. [CrossRef]

62. Caliani, I.; Rodríguez, L.P.; Casini, S.; Granata, A.; Zagami, G.; Pansera, M.; Querci, G.; Minutoli, R. Biochemical and genotoxic biomarkers in Atherina boyeri to evaluate the status of aquatic ecosystems. Reg. Stud. Mar. Sci. 2019, 28, 100566. [CrossRef]

63. Natura 2000 Network Viewer. Available online: https:/ / natura2000.eea.europa.eu/ (accessed on 10 January 2020). 
64. Lein, J.K. An expert system approach to environmental impact assessment. Int. J. Environ. Stud. 1989, 33, 13-27. [CrossRef]

65. Capoccioni, F.; Leone, C.; Belpaire, C.; Malarvannan, G.; Poma, G.; De Matteis, G.; Tancioni, L.; Contò, M.; Failla, S.; Covaci, A. Quality assessment of escaping silver eel (Anguilla anguilla L.) to support management and conservation strategies in Mediterranean coastal lagoons. Environ. Monit. Assess. 2020, 192, 570. [CrossRef] [PubMed]

66. Taylor, W.R.; Van Dyke, G.C. Revised procedures for staining and clearing small fishes and other vertebrates for bone and cartilage study. Cybium 1985, 9, 107-119.

67. Prestinicola, L.; Boglione, C.; Makridis, P.; Spanò, A.; Rimatori, V.; Palamara, E.; Scardi, M.; Cataudella, S. Environmental Conditioning of Skeletal Anomalies Typology and Frequency in Gilthead Seabream (Sparus aurata L., 1758) Juveniles. PLoS ONE 2013, 8, e55736. [CrossRef]

68. Harder, W. Anatomy of fishes. Part I: Text, E.; Schweizerbart'sche Verlagsbuchhandlung (Nägele u. Obermiller): Stuttgart, Germany, 1975; Volume 1, p. 612.

69. Pearson, K. LIII. On lines and planes of closest fit to systems of points in space. Lond. Edinb. Dublin Philos. Mag. J. Sci. 1901, 2, 559-572. [CrossRef]

70. Benzécri, J. L'analyse des données. L'analyse Corresp. 1973, 2, 619.

71. Benzécri, J.P.; Benzécri, F. L'analyse des Correspondances: Exposé Elémentaire; Dunod: Paris, France, 1984.

72. Hammer, Ø.; Harper, D.A.; Ryan, P.D. Past: Paleontological Statistics Software Package for Education and Data Analysis. Palaeontol. Electron. 2001, 4, 4-9.

73. Marfin, J.P. Les problèmes liés au polymorphisme de l'espèce Atherina boyeri Risso, 1810. Cybium 1984, 6, 16-29.

74. Creech, S. An electrophoretic investigation of populations of Atherina boyeri Risso, 1810 and A. presbyter Cuvier, 1829 (Teleostei: Atherinidae): Genetic evidence in support of the two species. J. Fish Biol. 1991, 39, 807-816. [CrossRef] 